\title{
Opening a new era of ABA research
}

\author{
Eiji Nambara $\cdot$ Kazuyuki Kuchitsu
}

Published online: 23 June 2011

(C) The Botanical Society of Japan and Springer 2011

\section{Introduction}

Abscisic acid (ABA) is a sesquiterpene plant hormone that regulates a variety of plant processes including seed dormancy, seed maturation, closure of stomata, and adaptive responses to abiotic and biotic stresses. It is 50 years since "abscisin" was originally reported (Liu and Carns 1961), but it has taken so many years of research to understand the basic mechanism of ABA perception and early signaling events (Cutler et al. 2010; Lumba et al. 2010).

The completion of the Arabidopsis genome sequencing project (Arabidopsis Genome Initiative 2000) and subsequent functional genomics approaches have had great impacts on elucidating the molecular mechanisms of many plant processes including ABA signaling. The discovery of the PYR1/PYL/RCAR receptors was reported independently by two groups and simplified our model of ABA action to a core signaling pathway (Ma et al. 2009; Park et al. 2009). The protein function of this family was solved by structural analysis immediately after these reports (Melcher et al. 2009, 2010; Miyazono et al. 2009; Nishimura et al. 2009; Peterson et al. 2010; Santiago et al.

\footnotetext{
E. Nambara

Department of Cell and Systems Biology, University of Toronto, Toronto, ON M5S 3B2, Canada

e-mail: eiji.nambara@utoronto.ca

K. Kuchitsu $(\bowtie)$

Department of Applied Biological Science,

Tokyo University of Science, Noda, Chiba 278-8510, Japan

e-mail: kuchitsu@rs.tus.ac.jp
}

2009; Yin et al. 2009). Furthermore, the ABA core signaling pathway has been functionally validated by in vitro re-constitution of ABA-induced gene expression (Umezawa et al. 2009; Fujii et al. 2009). ABA research has finally reached an exciting goal of dissecting a minimal pathway from hormone perception to transcriptional output.

Breakthroughs always produce new questions. As a journal proud of 124 years of history publishing a broad spectrum of research articles on basic plant biology, we are excited to invite internationally recognized scientists to comment on the "state of ABA" for this special issue with the aim of summarizing recent progress in ABA research and expand the core knowledge from Arabidopsis to a wide variety of plant species with special reference to phylogeny, evolution and ecology. We will discuss various aspects of ABA to foreshadow the future directions of this important field of research.

ABA metabolism and its signaling are responsive to both developmental and environmental cues, which makes this compound a key integrator of growth and development with the environment in plants. Higher plants synthesize ABA via oxidative cleavage of 9-cis-epoxycarotenoids (Zeevaart and Creelman 1988). ABA is catabolized through several pathways and ABA $8^{\prime}$-hydroxylation is a key step in inactivating ABA for many physiological processes (Nambara and Marion-Poll 2005). ABA-deficient and -insensitive mutants of various plant species display common phenotypes including reduced seed dormancy and wiltiness (Leung and Giraudat 1998; McCarty 1995). Molecular genetic analyses have identified $\sim 100$ Arabidopsis loci that alter ABA responsiveness (Finkelstein et al. 2002; Finkelstein et al. 2008). The molecular basis of ABA signaling has been most extensively analyzed in guard cells (Kim et al. 2010) and in stress physiology (Zhu 2002; Yamaguchi-Shinozaki and Shinozaki 2006). 


\section{Conservation and diversity of ABA related genes and their roles in evolution}

Current advances in completing the genome sequences of algae, mosses and ferns including Chlamydomonas reinhardtii (Merchant et al. 2007), Physcomitrella patens (Rensing et al. 2008) and Selaginella moellendorffii (Banks et al. 2011) have enabled us to discuss the evolution of ABA signaling. This genomic information also presents an important resource to provide insight into how metabolism and signaling pathways co-evolve to acquire the diverse functions of this important plant hormone. Similar to other plant hormones, ABA is synthesized by other organisms such as bacteria, fungi, and animals. Sakata and colleagues in this issue summarize our current knowledge of ABA production in various organisms and discuss its possible physiological roles (Takezawa et al. 2011). They also discuss the evolution of ABA metabolism and signaling in photosynthetic organisms. Another interesting aspect emerging from current genome information is the diversification of function and abundance of ABA related genes. Hanada et al. 2011 investigate the relationship between duplication of ABA-related genes and their functional divergence using bioinformaticsbased analysis.

ABA function is diversified in a wide variety of plant species. An interesting example is its key role as a switch between submersed and emersed life-styles in aquatic macrophytes. Wanke (2011) discusses functions of ABA in aquatic plants with special emphasis on both molecular and ecological aspects.

\section{ABA transport is a key for the systemic stress responses}

$\mathrm{ABA}$ is a mobile phytohormone, and its movement has been documented physiologically (Davies et al. 2005). Nonetheless, this fact is underestimated in the functional genomics approaches of plant stress physiology. Recent works reported the identification of two different $\mathrm{ABA}$ transporters in Arabidopsis (Kang et al. 2010; Kuromori et al. 2010). Seo and Koshiba (2011) review current knowledge on the ABA movement in relation to the sites of metabolism and perception of ABA. An important next challenge is to answer how stress response mechanisms in Arabidopsis are conserved in other plant species. Current work indicates that each cell type has unique functions in ABA action (Okamoto et al. 2009). The anatomical and functional diversity of plant cells among species suggests that systemic stress responses may differ between plant species, emphasizing the importance of comparative functional genomics research in different plant species.

\section{Mechanisms by which ABA activates individual processes}

One of the goals for plant biologists is to understand the mechanisms by which ABA triggers individual plant processes. This special issue presents two specific plant processes in which ABA plays important roles: its role in abiotic stress in stomatal guard cells and its role in biotic stress in plant-microbe interactions. Stomata are essential for land plants to regulate gas exchange and transpiration. Mori and Murata (2011) summarize research on stomatal regulation with particular emphasis on lessons from model plants other than Arabidopsis such as Vicia faba. They present comparative studies of ABA physiology in stomata, including the in vivo and in vitro characterization of stomatal responses.

Desveaux and colleagues discuss recent knowledge on the role of ABA in plant-pathogen interactions with emphasis on the Arabidopsis-Pseudomonas syringae model pathosystem (Cao et al. 2011). They also discuss the potential role of $\mathrm{ABA}$ in mediating the crosstalk between abiotic and biotic stress responses in plants.

\section{ABA core signaling pathway: multiple inputs and multiple outputs}

An important challenge in understanding ABA-induced physiology is linking these processes to the core $\mathrm{ABA}$ signaling pathway. One issue is the redundancy and diversity of the core signaling components: PRL1/PYL/ RCAR receptors, protein phosphatase $2 \mathrm{C}$ (PP2C), and SNF1-related protein kinase 2 (SnRK2). Fourteen PYR1/ PRL/RCAR receptors, 9 PP2C (Group A), and 3 SnRK2 (subfamily III) are potentially involved in ABA signaling in Arabidopsis (Umezawa et al. 2010). This core pathway activates 9 bZIP transcription (Group A) factors and other proteins (Hubbard et al. 2010). ABA-mediated transcription is one of the best characterized plant transcriptional responses and represents a promising output for the study of plant signal transduction. Transcriptome analyses have revealed that $\sim 10 \%$ of protein-coding genes are regulated by ABA. Multiple different $c i s$-acting elements and distinct members of transcription factor families are known to be involved in the regulation of ABA-mediated transcription. Yamaguchi-Shinozaki and colleagues in this issue review the recent literature dealing with ABA-mediated transcription (Fujita et al. 2011). Currently, transcriptome patterns are often used as a marker for a biological reaction rather than the expression of the single marker gene. The review article expands upon the use of ABA-regulated transcriptomes for the interpretation of complicated outputs. 
In addition to the PRL1/PYL/RCAR receptors, other proteins such as $\mathrm{Mg}$-chelatase $\mathrm{H}$ subunit (ChlH) (Shen et al. 2006), a G protein-coupled receptor (Liu et al. 2007), GPCR-type G proteins (Pandey et al. 2009) have also been reported to be involved in the ABA perception. It has been a challenge for the ABA researches to link these components to the well-established PRL1/PYL/RCAR-triggered signaling pathway. Tsuzuki et al. (2011) report that an Arabidopsis mutant with ABA-insensitive stomata is allelic to the $c h l h$ mutants. Importantly, ABA responsiveness of this mutant is restored when excess $\mathrm{Ca}^{2+}$ was applied. Due to the fact that they failed to detect the ABA binding to the $\mathrm{ChlH}$ protein in vitro, they conclude that $\mathrm{ChlH}$ is not an $\mathrm{ABA}$ receptor, but the $\mathrm{Mg}$-chelatase complex is involved in the ABA signaling in stomatal guard cells. Mg-chelatase is essential for the chloroplast function through involving the chlorophyll biosynthesis and the retrograde signaling. Examining the interaction between these processes and stomatal ABA signaling will be an attractive challenge in the future.

\section{Future perspectives}

Organisms have acquired numerous sophisticated mechanisms for their survival and fitness. The function and role of each mechanism cannot be discussed without considering the environment of individual plants in nature. ABA is a natural compound that has evolved to be a plant hormone together with its receptor and downstream machineries. Plant biologists have obtained a blueprint of how ABA is synthesized, perceived, and how its signal is transduced to the downstream events in Arabidopsis. A next challenge for plant biologists will be to utilize and integrate this basic information into the next generation of research.

We envision several future directions. For Arabidopsis research, it is apparent that researchers need to obtain a finer blueprint of ABA-signaling and corresponding physiological responses. Examples include addressing the redundancy and functional diversification of ABA-related gene families. Protein interactome and proteome analyses will represent key technologies to address these questions. The knowledge of ABA function will need to be integrated into a mechanistic understanding of biological systems, which are composed of networks with multiple inputs and outputs. Systems biology approaches will also be important to answer questions of network biology, such as those related to hormone crosstalk. Umezawa (2011) discusses the systems biology approaches of ABA research. An important challenge will be the elucidation of $\mathrm{ABA}$ function in each cell type with the ultimate goal of presenting a 3D-rendering of cellular ABA-responses. Sophisticated technologies are necessary to draw the blueprint of ABA function, such as sorting specific cell types, laser microdissection (Endo et al. 2008), and live imaging systems (Christmann et al. 2005). Emerging novel research strategies will undoubtedly also be essential for our understanding of ABA biology.

Kitahata and Asami (2011) review recent chemical biology research on $\mathrm{ABA}$, and discuss the usefulness of chemical biology approaches. ABA research has already provided some elegant examples of the use of chemical genetics to dissect biological processes (McCourt and Desveaux 2010). In addition, the development of a wide variety of ABA analogs and inhibitors for ABA metabolism will provide powerful tools for future pure and applied research (Ueno et al. 2005; Todoroki et al. 2008; Zaharia et al. 2005; Kitahata and Asami 2011).

ABA research continues to greatly benefit from Arabidopsis genomics. In addition, new genome sequences are constantly being released which will continue to expand our understanding of ABA signaling across the plant kingdom. This meta-genome data will not only provide us with novel information and resources, but also provide novel methodologies, technologies and concepts. The accumulating knowledge on the stress physiology of ABA as well as functional genomics promise exciting advances in the phylogenetic, ecological and evolutionary aspects of ABA research.

Acknowledgments The authors thank Drs. Peter McCourt and Darrell Desveaux for comments and suggestions.

\section{References}

Arabidopsis Genome Initiative (2000) Analysis of the genome sequence of the flowering plant Arabidopsis thaliana. Nature 408:796-815

Banks JA, Nishiyama T, Hasebe M, Bowman JL, Gribskov M, Depamphilis C, Albert VA, Aono N, Aoyama T, Ambrose BA et al (2011) The Selaginella genome identifies genetic changes associated with the evolution of vascular plants. Science 332:960-963

Cao FY, Yoshioka K, Desveaux D (2011) The roles of ABA in plantpathogen interactions. J Plant Res 124. doi:10.1007/s10265011-0409-y

Christmann A, Hoffmann T, Teplova I, Grill E, Muller A (2005) Generation of active pools of abscisic acid revealed by in vivo imaging of water-stressed Arabidopsis. Plant Physiol 137: 209-219

Cutler SR, Rodriguez PL, Finkelstein RR, Abrams SR (2010) Abscisic acid: emergence of a core signaling network. Annu Rev Plant Biol 61:651-679

Davies WJ, Kudoyarova G, Hartung W (2005) Long-distance ABA signaling and its relation to other signaling pathways in the detection of soil drying and the mediation of the plant's response to drought. J Plant Growth Regul 24:285-295

Endo A, Sawada Y, Takahashi H, Okamoto M, Ikegami K, Koiwai H, Seo M, Toyomasu T, Mitsuhashi W, Shinozaki K et al (2008) Drought induction of Arabidopsis. 9-cis-epoxycarotenoid dioxygenase occurs in vascular parenchyma cells. Plant Physiol 147:1984-1993 
Finkelstein RR, Gampala SSL, Rock CD (2002) Abscisic acid signaling in seeds and seedlings. Plant Cell 14:S15-S45

Finkelstein R, Reeves W, Ariizumi T, Steber C (2008) Molecular aspects of seed dormancy. Annu Rev Plant Biol 59:387-415

Fujii H, Chinnusamy V, Rodrigues A, Rubio S, Antoni R, Park SY, Cutler SR, Sheen J, Rodriguez PL, Zhu JK (2009) In vitro reconstitution of an abscisic acid signalling pathway. Nature 462:660-664

Fujita Y, Fujita M, Shinozaki K, Yamaguchi-Shinozaki K (2011) ABA-mediated transcriptional regulation in response to osmotic stress in plants. J Plant Res 124. doi:10.1007/s10265-011-0412-3

Hanada K, Hase T, Toyoda T, Shinozaki K, Okamoto M (2011) Origin and evolution of genes related to ABA metabolism and its signaling pathways. J Plant Res 124. doi:10.1007/s10265011-0431-0

Hubbard KE, Nishimura N, Hitomi K, Getzoff ED, Schroeder JI (2010) Early abscisic acid signal transduction mechanisms: newly discovered components and newly emerging questions. Genes Dev 24:1695-1708

Kang J, Hwang JU, Lee M, Kim YY, Assmann SM, Martinoia E, Lee Y (2010) PDR-type ABC transporter mediates cellular uptake of the phytohormone abscisic acid. Proc Natl Acad Sci USA 107:2355-2360

Kim TH, Böhmer M, Hu H, Nishimura N, Schroeder JI (2010) Guard cell signal transduction network: advances in understanding abscisic acid, $\mathrm{CO}_{2}$, and $\mathrm{Ca}^{2+}$ signaling. Annu Rev Plant Biol 61:561-591

Kitahata N, Asami T (2011) Chemical biology of abscisic acid. J Plant Res 124. doi:10.1007/s10265-011-0415-0

Kuromori T, Miyaji T, Yabuuchi H, Shimizu H, Sugimoto E, Kamiya A, Moriyama Y, Shinozaki K (2010) ABC transporter AtABCG25 is involved in abscisic acid transport and responses. Proc Natl Acad Sci USA 107:2361-2366

Leung J, Giraudat J (1998) Abscisic acid signal transduction. Ann Rev Plant Physiol Plant Mol Biol 49:199-222

Liu W-C, Carns HR (1961) Isolation of abscisin, an abscission accelerating substance. Science 134:384-385

Liu X, Yue Y, Li B, Nie Y, Li W, Wu W-H, Ma L (2007) A G protein-coupled receptor is a plasma membrane receptor for the plant hormone abscisic acid. Science 315:1712-1716

Lumba S, Cutler S, McCourt P (2010) Plant nuclear hormone receptors: a role for small molecules in protein-protein interactions. Annu Rev Cell Dev Biol 26:445-469

Ma Y, Szostkiewicz I, Korte A, Moes D, Yang Y, Christmann A, Grill E (2009) Regulators of PP2C phosphatase activity function as abscisic acid sensors. Science 324:1064-1068

McCarty DR (1995) Genetic control and integration of maturation and germination pathways in seed development. Annu Rev Plant Physiol Plant Mol Biol 46:71-93

McCourt P, Desveaux D (2010) Plant chemical genetics. New Phytol 185:15-26

Melcher K, Ng LM, Zhou XE, Soon FF, Xu Y, Suino-Powell KM, Park SY, Weiner JJ, Fujii H, Chinnusamy V et al (2009) A gatelatch-lock mechanism for hormone signalling by abscisic acid receptors. Nature 462:602-608

Melcher K, Xu Y, Ng LM, Zhou XE, Soon FF, Chinnusamy V, SuinoPowell KM, Kovach A, Tham FS, Cutler SR et al (2010) Identification and mechanism of ABA receptor antagonism. Nat Struct Mol Biol 17:1102-1108

Merchant SS, Prochnik SE, Vallon O, Harris EH, Karpowicz SJ, Witman GB, Terry A, Salamov A, Fritz-Laylin LK, MaréchalDrouard L et al (2007) The Chlamydomonas genome reveals the evolution of key animal and plant functions. Science 318:245-250

Miyazono K, Miyakawa T, Sawano Y, Kubota K, Kang HJ, Asano A, Miyauchi Y, Takahashi M, Zhi Y, Fujita Y et al (2009) Structural basis of abscisic acid signalling. Nature 462:609-614
Mori IC, Murata Y (2011) ABA signaling in stomatal guard cells: lessons from Commelina and Vicia. J Plant Res 124. doi: 10.1007/s10265-011-0435-9

Nambara E, Marion-Poll A (2005) Abscisic acid biosynthesis and catabolism. Annu Rev Plant Biol 56:165-185

Nishimura N, Hitomi K, Arvai AS, Rambo RP, Hitomi C, Cutler SR, Schroeder JI, Getzoff ED (2009) Structural mechanism of abscisic acid binding and signaling by dimeric PYR1. Science 326:1373-1379

Okamoto M, Tanaka Y, Abrams SR, Kamiya Y, Seki M, Nambara E (2009) High humidity induces abscisic acid 8'-hydroxylase in stomata and vasculature to regulate local and systemic abscisic acid responses in Arabidopsis. Plant Physiol 149:825-834

Pandey S, Nelson DC, Assmann SM (2009) Two novel GPCR-type G proteins are abscisic acid receptors in Arabidopsis. Cell 136:136-148

Park S, Fung P, Nishimura N, Jensen DR, Fujii H, Zhao Y, Lumba S, Santiago J, Rodrigues A, Chow TF et al (2009) Abscisic acid inhibits type $2 \mathrm{C}$ protein phosphatases via the PYR/PYL family of START proteins. Science 324:1068-1071

Peterson FC, Burgie ES, Park SY, Jensen DR, Weiner JJ, Bingman CA, Chang CE, Cutler SR, Phillips GN Jr, Volkman BF (2010) Structural basis for selective activation of ABA receptors. Nat Struct Mol Biol 17:1109-1113

Rensing SA, Lang D, Zimmer AD, Terry A, Salamov A, Shapiro H, Nishiyama T, Perroud PF, Lindquist EA, Kamisugi $Y$ et al (2008) The Physcomitrella genome reveals evolutionary insights into the conquest of land by plants. Science 319:64-69

Santiago J, Dupeux F, Round A, Antoni R, Park SY, Jamin M, Cutler SR, Rodriguez PL, Márquez JA (2009) The abscisic acid receptor PYR1 in complex with abscisic acid. Nature 462:665-668

Seo M, Koshiba T (2011) Transport of ABA from the site of biosynthesis to the site of action. J Plant Res 124. doi: 10.1007/s10265-011-0411-4

Shen Y-Y, Wang X-F, Wu F-Q, Du S-Y, Cao Z, Shang Y, Wang X-L, Peng C-C, Yu X-C, Zhu S-Y et al (2006) The Mg-chelatase H subunit is an abscisic acid receptor. Nature 443:823-826

Takezawa D, Komatsu K, Sakata Y (2011) ABA in bryophytes: how a universal growth regulator in life became a plant hormone? J Plant Res 124. doi:10.1007/s10265-011-0410-5

Todoroki Y, Kobayashi K, Yoneyama H, Hiramatsu S, Jin MH, Watanabe B, Mizutani M, Hirai N (2008) Structure-activity relationship of uniconazole, a potent inhibitor of ABA 8'hydroxylase, with a focus on hydrophilic functional groups and conformation. Bioorg Med Chem Lett 16:3141-3152

Tsuzuki T, Takahashi K, Inoue S, Okigaki Y, Tomiyama M, Hossain MA, Shimazaki K, Murata Y, Kinoshita T (2011) Mg-chelatase $\mathrm{H}$ subunit affects ABA signaling in stomatal guard cells, but is not an ABA receptor in Arabidopsis thaliana. J Plant Res 124. doi:10.1007/s10265-011-0426-x

Ueno K, Yoneyama H, Saito S, Mizutani M, Sakata K, Hirai N, Todoroki Y (2005) A lead compound for the development of ABA 8'-hydroxylase inhibitors. Bioorg Med Chem Lett 15:5226-5229

Umezawa T (2011) Systems biology approaches to abscisic acid signaling. J Plant Res 124. doi:10.1007/s10265-011-0418-x

Umezawa T, Sugiyama N, Mizoguchi M, Hayashi S, Myouga F, Yamaguchi-Shinozaki K, Ishihama Y, Hirayama T, Shinozaki K (2009) Type 2C protein phosphatases directly regulate abscisic acid-activated protein kinases in Arabidopsis. Proc Nat Acad Sci USA 106:17588-17593

Umezawa T, Nakashima K, Miyakawa T, Kuromori T, Tanokura M, Shinozaki K, Yamaguchi-Shinozaki K (2010) Molecular basis of the core regulatory network in ABA responses: sensing, signaling and transport. Plant Cell Physiol 51:1821-1839 
Wanke D (2011) The ABA-mediated switch between submersed and emersed life-styles in aquatic macrophytes. J Plant Res 124. doi: 10.1007/s10265-011-0434-x

Yamaguchi-Shinozaki K, Shinozaki K (2006) Transcriptional regulatory networks in cellular responses and tolerance to dehydration and cold stresses. Annu Rev Plant Biol 57:781-803

Yin P, Fan H, Hao Q, Yuan X, Wu D, Pang Y, Yan C, Li W, Wang J, Yan N (2009) Structural insights into the mechanism of abscisic acid signaling by PYL proteins. Nat Struct Mol Biol $16: 1230-1236$
Zaharia LI, Walker-Simmon MK, Rodriguez CN, Abrams SR (2005) Chemistry of abscisic acid, abscisic acid catabolites and analogs. J Plant Growth Regul 24:274-284

Zeevaart JAD, Creelman RA (1988) Metabolism and physiology of abscisic acid. Annu Rev Plant Physiol Plant Mol Biol 39:439-473

Zhu JK (2002) Salt and drought stress signal transduction in plants. Annu Rev Plant Biol 53:247-273 